The aim of this presentation is to provide insight into the pitfalls of imaging in diagnosing $\mathrm{SpA}$, with a particular focus on false positives in imaging as well as the importance of interpretation of the clinical context.

Disclosure of Interests: None declared

DOI: 10.1136/annrheumdis-2019-eular.8610

\section{SP0195 IMAGING IN DISEASE AND TREATMENT MONITORING - DOES IT MATTER?}

Xenofon Baraliakos. Rheumazentrum Ruhrgebiet, Ruhr University Bochum, Rheumatology, 44649 Herne, Germany

Background: Imaging of the axial skeleton is a crucial step in classification and diagnosis of axial Spondyloarthritis. After diagnosis, patients with axSpA are being treated with non-steroidal anti-inflammatory drugs (NSAIDs) or with disease-modifying anti-rheumatic drug (bDMARD). Despite the fact, that the latter treatment is referred to as disease-modifying and modification of the disease is supposed to be relating to the objective course of the disease, as assessed by imaging, recommendations for monitoring of the course of axSpA by imaging are still lacking mostly due to the lack of data. Nevertheless, this aspect is mentioned in the treat-to-target principle for axSpAOverall, earlier data have shown that the course of lesions documented by magnetic resonance imaging (MRI) is correlating well with other objective measures of changes of systemic inflammation such as c-reactive protein (CRP), than with patient-reported measures of disease activity. Similarly, conventional radiographs $(\mathrm{CR})$ are being used for documenting of the development of structural changes over many years.

Objectives: The objective of this presentation is to show the current evidence of the possibilities of different imaging techniques used in axSpA for assessment of the course of the disease (both for the inflammatory and chronic changes) and give practical tips about when imaging would be advised for monitoring the disease course or where this can be avoided.

Disclosure of Interests: Xenofon Baraliakos Grant/research support from: AbbVie, Boehringer Ingelheim, Bristol-Myers Squibb, Celgene, Centocor, Chugai, Janssen, MSD, Novartis, Pfizer Inc, Roche and UCB, Grant/research support from: AbbVie, Pfizer, Merck Sharp \& Dohme, UCB Pharma, Novartis, Consultant for: AbbVie, Bristol-Myers Squibb, Boehringer Ingelheim, Celgene, Chugai, Janssen Biologics, Novartis, Pfizer, UCB Pharma, Galapagos, Speakers bureau: AbbVie, Chugai, Janssen, Novartis, Pfizer, UCB Pharma

DOI: 10.1136/annrheumdis-2019-eular.8424

\section{SP0196 IS THERE ROOM FOR OTHER IMAGING MODALITIES BEYOND CONVENTIONAL X-RAYS AND MRI?}

C.J. van der Laken. Amsterdam UMC location VUmc, Rheumatology, Amsterdam, Netherlands

Early diagnosis of spondyloarthritis is still tempting since objective measures to assess disease activity are often negative. MRI provides highly sensitive visualization of inflammation, but detection levels in early spondyloarthitis are varying Another clinical temptation is early treatment evaluation of spondyloarthritis. An important outcome measure is therapeutic efficacy on bone formation in vertebral column and sacro-iliac joints. Conventional $\mathrm{X}$-rays only allow for assessment of bone formation over a time span of at least 2 years. In this presentation, opportunities with new upcoming imaging techniques to address above mentioned clinical issues will be discussed in relation to longer existing imaging techniques.

Disclosure of Interests: None declared

DOI: 10.1136/annrheumdis-2019-eular.8609

SATURDAY, 15 JUNE 2019

12:00:00 - 13:30:00

\section{The lung in rheumatoid arthritis}

\section{SP0197 CASE 1 PRESENTER: EARLY RA WITH LUNG PROBLEMS IN THE CONTEXT OF BIOLOGICAL TREATMENT}

Ana Milena Millán Arciniegas. Santa Creu i Sant Pau Hospital, Rheumatology, Barcelona, Spain

We present a 77-year-old male patient with a history of former smoker, arterial hypertension and dyslipidaemia, whose diagnosis of Rheumatoid Arthritis was made in July 2017 by arthritis of metacarpophalangeal joints, wrists and knees and positivity for anticyclic citrullinated peptide antibodies (ACPA) and rheumatoid factor (RF). Treatment with Methotrexate and prednisone was started but the patient did not achieve adequate control of joint symptoms, so we decided to add Etanercept to the treatment. A good joint response was obtained but in a follow-up control he explained breathlessness with cough and low grade fever. The chest $X$ Ray was not conclusive and we decided to perform a high resolution computerized tomography (HRCT) scan. An interstitial involvement was detected and an accurate differential diagnosis was made.

Disclosure of Interests: None declared

DOI: 10.1136/annrheumdis-2019-eular. 8538

\section{SP0198 CASE 1 DISCUSSANT: HOW TO DIFFERENTIATE ILD FROM OTHER CAUSES OF LUNG INVOLVEMENT IN RA}

Ivan Castellvi. Hospital Universitari de la Santa Creu i Sant Pau, Rheumatology, Barcelona, Spain

The lung in Rheumatoid Arthritis (RA) can be affected by different manifestations and Interstitial Lung Disease (ILD) related to RA is one of the most devastating complications that we can find in the disease. The lung parenchyma involvement can be present with different patterns. As opposite with other forms of connective tissue diseases the usual interstitial pneumonia pattern (UIP) is more frequent than nonspecific interstitial pneumonia pattern (NSIP) in RA. Currently high-resolution computed tomography (HRCT) and pulmonary function test are the best tools to detect and to follow ILD in RA. Nevertheless, other lung involvements infections and drug toxicity of nonbiological and biological disease-modifying antirheumatic drugs (DMARDs) can affect patients with rheumatoid arthritis and simulate ILD. To know which affectation are present in our patients with interstitial lung compromise is crucial to proceed against the problem. Patient characteristics, clinical presentation, radiological distribution or bronchoalveolar lavage would be helpful to discriminate ILD from other causes of lung involvement. An individual and multidisciplinary approach is very important to do the best management in these patients.

Disclosure of Interests: None declared

DOI: 10.1136/annrheumdis-2019-eular.8443

\section{SP0199 CASE 2 DISCUSSANT: HOW TO TREAT DIFFICULT ILD}

Toby Maher. Imperial College London and Royal Brompton Hospital, National Heart and Lung Institute, London, United Kingdom

Background: ILD frequently results in progressive and irreversible destruction of the lung through scarring. Prompt therapy can help rescue lung function and prevent subsequent respiratory decline. This case will demonstrate the challenges inherent in diagnosing and managing interstitial lung disease in the context of connective tissue disease

Objectives: To discuss typical presentation of CTD-ILD

Review challenge of making diagnosis and choosing best treatment.

Assess treatment options, duration of therapy and measurement of treatment response.

Conclusion: A range of therapeutic options exist for CTD-ILD albeit with a paucity of trial data to support best practice. Accurate diagnosis of systemic disease, paired with careful assessment and monitoring of the respiratory system are vital in ensuring optimal management. Intravenous therapy is often necessary in advanced disease or for disease which proves refractory to ora immunosuppression.

\section{REFERENCES:}

[1] Saunders P, Tsipouri V, Keir GJ, Ashby D, Flather MD, Parfrey H, Babalis D, Renzoni EA, Denton CP, Wells AU, Maher TM. Rituximab versus cyclophosphamide for the treatment of connective tissue disease-associated interstitial lung disease (RECITAL): study protocol for a randomised controlled trial. Trials 2017; 18: 275 .

[2] Maher TM. Immunosuppression for connective tissue disease-related pulmonary disease. Seminars in respiratory and critical care medicine 2014; 35: 265-273.

Disclosure of Interests: Toby Maher Grant/research support from: Received funds from $\mathrm{Bl}$ advisory board participation and conference travel. Received research funding and/or consulting fees or other remuneration from GSK, UCB, AstraZeneca, Roche, Bayer, Biogen Idec, Cipla, Prometic, and Sanumed. Toby Maher has, via his institution, received industry-academic funding from GlaxoSmithKline R\&D and UCB., Consultant for: Toby Maher has received consultancy or speakers fees from Apellis, AstraZeneca, Bayer, Biogen Idec, Boehringe Ingelheim, Galapagos, GlaxoSmithKline R\&D, Indalo, Pliant, ProMetic, Roche, Samumed and UCB; and has received consultancy fees from Galecto. DOI: 10.1136/annrheumdis-2019-eular.853 
SATURDAY, 15 JUNE 2019

12:00:00 - 13:30:00

\section{Novel treatments and old challenges: where do we stand in the management of antiphospholipid syndrome}

\section{SP0200 1 TARGETED TREATMENTS: WHAT'S ON THE HORIZON FOR OBSTETRIC ANTIPHOSPHOLIPID SYNDROME?}

Jane E. Salmon. Hospital for Special Surgery - Weill Cornell Medicine,

Rheumatology, New York, United States of America

Pregnancy in women with APS and/or lupus is dangerous both for mother and offspring, and, in the past, patients were advised not to have children. Among complications frequently seen in women with lupus are preeclampsia (also known as toxemia of pregnancy), preterm birth, markedly underweight newborns, and fetal death. Identifying women destined for complications remains challenging and limits our ability to counsel and care for pregnant lupus patients.

There is currently no effective treatment for women with these high-risk pregnancies; treatments to prevent poor pregnancy outcomes require an understanding of mechanisms of injury. Our research in an animal model that mimics the human condition shows that blockade of well-established mediators of inflammation, specifically complement and TNF-alpha, prevents adverse outcomes. To translate these discoveries to lupus patients, we launched the PROMISSE Study (Predictors of pRegnancy Outcome: bioMarkers In antiphospholipid antibody Syndrome and Systemic lupus Erythematosus) to determine which pregnancies were at highest risk for adverse outcomes. Over $20 \%$ of pregnancies in patients with SLE resulted in an adverse pregnancy outcome. We discovered that the presence of a lupus anticoagulant which can be detected in the blood before pregnancy or in the first trimester, confers a 10-fold increase in risk of complications. Furthermore, we found that early in pregnancy, measurable alterations in the balance of angiogenic factors (proteins that circulate in blood, promote proper placenta development, and are required to maintain the health of the mother's vascular system) are highly predictive of preeclampsia and other pregnancy complications.

The results of the PROMISSE Study provide models for early risk stratification to allow physicians to identify patients early in pregnancy who are at low risk and reassure them that their pregnancies were likely to be uncomplicated and their babies healthy. Conversely and importantly, we can reliably predict which patients are destined to have poor pregnancy outcomes, and we conducting a trial with a TNF-alpha inhibitor that does not cross the placenta in patients at highest risk an experimental therapy to prevent placental dysfunction. Treatments to prevent poor pregnancy outcomes require an understanding of mechanisms of injury. Experiments in mouse models have enabled us to embark upon a trial of a potential treatment.

Disclosure of Interests: Jane E. Salmon Shareholder of: Biogen-Idec, BMS, Johnson \& Johnson, Regeneron, Merck, Grant/research support from: UCB, Consultant for: BMS, Ionis

DOI: 10.1136/annrheumdis-2019-eular.8581

\section{SP0201 CATASTROPHIC APS TREATMENT GUIDELINES}

Ricard Cervera. Hospital Clinic, Barcelona, Department of Autoimmune Diseases, Barcelona, Spain

The current recommendation for specific therapy of catastrophic antiphospholipid syndrome (CAPS) is the triple therapy with anticoagulation, glucocorticoids, plasma exchange and/or intravenous immunoglobulins. Of note, only anticoagulation had a significant effect improving the vital prognosis of these patients. From the experimental point of view, there is only indirect evidence to advocate the use of these immunomodulatory therapies in CAPS.

Recently, two monoclonal antibodies, rituximab and eculizumab, have been successfully used in some cases of severe or refractory CAPS. The first decreases the generation of pathogenic autoantibodies such as antiphospholipid. The second prevents the generation of C5b-C9 complex.

The current presentation will describe the conventional and recent modalities of CAPS treatment, discussing the rationale for each one.

\section{REFERENCES:}

[1] Cervera R, Rodríguez-Pintó I, Espinosa G. The diagnosis and clinical management of the catastrophic antiphospholipid syndrome: A comprehensive review. J Autoimmun 2018; 92: 1-11.

[2] Rodríguez-Pintó I, Espinosa G, Cervera R. Catastrophic antiphospholipid syndrome: The current management approach. Best Pract Res Clin Rheumatol 2016; 30: 239-249.
[3] Rodriguez-Pintó I, Santacreu I, Cervera R, Espinosa G. What is the best strategy in treating catastrophic antiphospholipid syndrome? Int $\mathrm{J}$ Clin Rheumtol 2015;10: 245-255

[4] Rodríguez-Pintó I, Espinosa G, Erkan D, Shoenfeld Y, Cervera R, for the CAPS Registry Project Group. The effect of triple therapy on the mortality of catastrophic antiphospholipid syndrome. Rheumatol 2018; 57: 12641270.

Disclosure of Interests: None declared

DOI: 10.1136/annrheumdis-2019-eular.8444

SATURDAY, 15 JUNE 2019

12:00:00 - 13:30:00

\section{How low should you go? What is the relevant target in T2T in rheumatoid arthritis?}

\section{SP0202 WHAT DOES REMISSION MEAN FOR PHYSICIANS?}

Laure Gossec. Sorbonne Universite and Pitie-Salpetriere Hospital, Rheumatology, Paris, France

Remission is the announced objective is rheumatoid arthritis. However, there are several definitions of remission. In this talk, we will review different health profes sional based definitions of remission, the components of these definitions, and their advantages and drawbacks.

Disclosure of Interests: Laure Gossec Grant/research support from: AbbVie, BMS, Celgene, Janssen, Lilly, MSD, Novartis-Sandoz, Pfizer, Sanofi, and UCB Consultant for: AbbVie, Biogen, BMS, Celgene, Janssen, Lilly, MSD, Nordic Pharma, Novartis-Sandoz, Pfizer, Roche, Sanofi, and UCB, Consultant for: L Gossec has received honoraria from Celgene as investigator for this study DOI: 10.1136/annrheumdis-2019-eular.8486

\section{SP0203 WHAT DOES REMISSION MEAN FOR PATIENTS?}

Ruth Williams. Kings College London, Department of Inflammation Biology, London, United Kingdom

What does remission in Rheumatoid arthritis mean to patient?

This session discusses what remission means to patients. Remission holds differ ent meaning for researchers, clinicians and patients. In addition it holds different meaning for individual patients and for individual patients at different points of time in their lives. I shall reflect on over fifty years living with Rheumatoid arthritis, as both a patient and a doctor. To consider the changes in my care, my therapy and in my own and my clinicians objectives and treatment aims, at different points in time. Looking at how things have progressed from pain relief, splinting, physica therapy, rehabilitation and surgery. To progressively more effective DMARD's antl-TNF's \& Biologics and an aim of complete 'clinical remission'.

However commonly 'clinical remission' can conflict with a patients concept of remission, as patients are individuals and the tools used to define remission are research based and consider populations not people. 'Disease activity scoring' and 'Treat to Target' has had significant impact on patients, clinicians and their rheumatology consultations. The absence of inflammation does not equal remission for many patients and it is important to consider the differing needs of patients who were diagnosed pre and post- biologic therapies and those with refractory disease. Currently maximal energy appears to be concentrated on the newly diagnosed and even pre-diagnosis, but has this been at the detriment of those with long established disease?

I will share my own and different patients viewpoints of what 'remission' means and consider the benefits of progress in effective 'therapies' but also to reflect upon some of the important things that may have been lost from clinical 'care' along the way. To list simple things that can help patients achieve remission that can easily be forgotten. I will explain the phenomenon of 'DAS blindness' and the potential failings it can lead to. Discuss how improved shared decision making of treatment aims might improve outcomes for patients whilst reducing risk and possibly costs; aiming to increase patient autonomy and improve the doctor patient dynamic.

In order to achieve 'remission' for patients we need to have a clear shared understanding of what 'remission' means to each individual and only then can we aim to achieve it.

Disclosure of Interests: None declared

DOI: 10.1136/annrheumdis-2019-eular.8620 